stehen, wie das nach $t$ stehende $r$ die assimilation der dentale zu $t$ hätte hindern können. Dagegen ist es sehr leicht begreiflich, wie der enge anschluss des ersten dentals an einen vorhergehenäen consonanten dle angleichung unmöglich machte und die selbständigkeit des ersten dentals auch bei oxytonierung bis zu dem zeitpunkte erhielt, wo das neue lautgesetz der assimilation der dentalis vor dentalis in der sprache wirksam wurde. Dann fielen auch diese lautgruppen mit dem alten st zusammen.

LEIPZIG, 13. august $1879 . \quad$ RUDOLF KÖGEL.

\title{
ZU UNSER VROUWEN KLAGE.
}

(Beitr. V, s. 193.)

In der genannten abhandlung habe ich s. 291 ff. den nachweis zu fuhren versucht, dass die Interrogatio sancti Anshelmi de passione domini das von dem dichter von Uvkl. bezeichnete buchlein gewesen sei, aus dessen lectüre er die anregung zu seinem epos empfangen und auch den wesentlichsten teil des stoffes geschöpft habe. Die meisten und wichtigsten beweisstlucke fanden sich jedoch nicht in der yon Schade auf grund zweier Giessener handscbriften veranstalteten ausgabe der Interrogatio, sondern in jenem der Leipziger pergamenthandschrift no. 368 entnommenen Planctus Mariae, wolchen C. Schröder als eine ergänzung des Giessener textes, Germ. 17, s. 231 ff., zum abdruck gebracht hatte. Wenn sich nun allerdings auch in diesem Planctus, seiner tendenz entsprechend, der kern des gedichtes, die klage Mariens uber den gekreuzigten sohn concentrierte, so blieb der äusserst lose zusammenhang dieses mit den übrigen partien der Interrogatio immerhin auffallend, und da die letztere auch in bezug auf das vom dichter selbst gegebene kennzeichen, dass das von ilum benutzte büchlein mit dem guis dabit capiti meo fonlem lacrimarum ete. Jeremias 9,1 beginne, nur unvollkommen entsprach, weil diese stelle in der Interrogatio erst im verlaufe der erzählung (bei Schade s. 7, 1. 2) auftritt, so glaubte ich schon Beitr. V, s. 295 anm. 1 die vermutung aussprechen zu 
mulssen, dass der Planctus der Leipziger handschrift vielleicht nur eine interpolation sei. Diese vermutung hat sich nunmehr in der tat bestätigt; denn er ist nur eine entlehnung aus dem Tractatus beati Bernardi de planctu beate Marie virginis, und dieser tractat also ist, da er auch mit dem Quis dabit capiti meo etc. anfängt und durchweg in dem deutschen gedichte reproduciert wurde, als die eigentliche quelle des dichters zu betrachten.

$\mathrm{Zu}$ meinem bedauern hat es mir bisher an zeit gefehlt, das längst vollständig gesammelte material auszuarbeiten, welches als III. teil meiner abhandlung die ausserordentliche verbreitung des gedichtes im 14. und 15. jahrhundert und seine benutzung in einer grossen anzahl späterer dichtungen nachweisen soll, womit erst seine hervorragende bedeutung fur die geistes- und geschmacksrichtung in diesem zeitraume ins rechte licht gesetzt werden wird, vgl. z. b. meine Oster- und passionsspiele s. V anmerkung. Ich darf indessen hoffen dass ich noch während der wintermonate die erwlinschte musse finde und diesen rest im nächsten oder spätestens im nächstfolgenden hefte dieser beiträge mitteilen kann. Da sich die wichtigkeit der lateinischen quelle auch fur die textkritik unseres gedichtes schon in dem erwähnten abschnitt meiner -abhandlung ergeben hat, so werde ich meine arbeit mit einem abdruck des tractates des h. Bernhard beschliessen milssen. Leider nur scheinen ältere handsch: ften desselben, deren mir nur eine Munchener aus dem 14. jahrhundert bekannt ist, ziemlich selten zu sein; ich wurde daher fur die freundliche nachweisung von handschriften des 13./14. jahrhunderts besonders dankbar sein.

WOLFENBÜ'I'I'EL.

GUS'TAV MILCHSAC'K. 


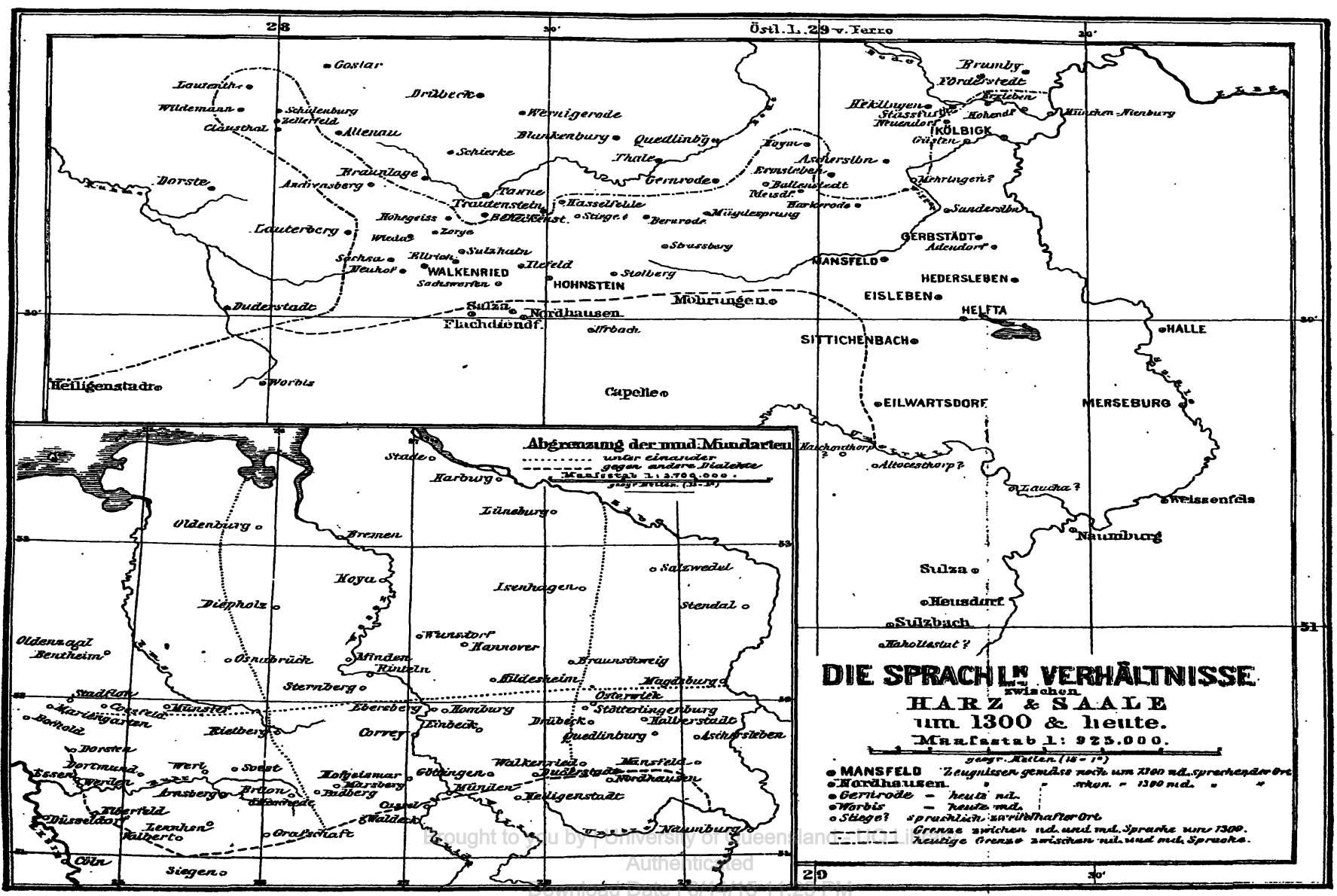

